\title{
Inhaltsverzeichnis des dritten Bandes
}

\author{
$(\S \S 343-372)$ \\ Drittes Buch \\ Handelsgeschäft \\ Seite
}

Erster Abschnitt

Allgemeine Vorschriften

Vorbemerkungen ......... . 1

§343 Die Handelsgeschäfte . . .

\$344 Vermutung für die Zuge-

hörigkeit der Rechtsge-

schäfte eines Kaufmanns

zum Handelsbetrieb. Die von

einem Kaufmann gezeich-

neten Schuldscheine. . . .

§ 345 Einseitige Handelsgeschäfte

§346 Rücksichtnahme unter Kaufleuten auf die im Handelsverkehr geltenden Gewohnheiten und Gebräuche. Auslegung von Willenserklärungen. Bedeutung d. Schweigens im Handelsverkehr. Geschäftsbedingungen. Treu $u$. Glauben bei Vertragserfüllung. . . . . . . . . .

Anhang zu $\S 346$.

I. Unsittliche Geschäfte. Einzelfragen: Bierabnahmevertrag; Warenbezugsverträge; Knebelungsverträge, Schweigevertrag; Schmiergelder; Abhalten vom Bieten; Ausschreibungen; ehrenwörtliche Bindung; Scheingeschäfte; verbotene Geschäfte; illegale Handlungen; Streik, Boykott, Aussperrung. . . . .

II. Erzwingung des Vertragsabschlusses und von Freizeichnungen ...... .

III. Unmöglichkeit und Verpflichtungsgrenze. Fortfall und Veränderung der $\mathrm{Ge}$ schäftsgrundlage . . . . .

§347 Sorgfalt eines ordentlichen Kaufmanns. Verschulden vor Vertragsabschluß. Milderungen der Haftung, ursächlicher Zusammenhang. Art und Umfang der Schadensersatzpflicht. Ausgleichung von Vorteil und Schaden. Schuldhafte Mitverursachung des Schadens durch den Geschädigten. Ausschluß der Haftung durch Vertrag 131 Bis hierher Lieferung 1; Material bis Anfang 1953 verarbeitet

$2 \S 348$ Die von einem Kaufmann im Betrieb seines Handelsgewerbes versprochene Vertragsstrafe . . . . . . 156

Anhang zu $\$ 348$. Reuegeld . . . . 169

$\S 349$ Bürgschaft. Kreditbürgschaft. Mitbürgen. Rückbürgschaft. Schuldmitübernahme. Kreditauftrag. Kreditvertrag. Garantievertrag . 171

Anhang zu §349. Rat, Empfehlung, Auskunft . . . . . . 212

\$350 Form der Bürgschaft, des Schuldversprechens, des Schuldanerkenntnisses. Folgen der Formverletzung . . 228

§351 Geschäfte des Minderkauf13

\$353 Verzinslichkeit der Forderungen aus beiderseitigen Handelsgeschäften . . . . 249

§354 Anspruch des Kaufmanns für Mühewaltung, Dienstleistung, Aufbewahrung auf Provision, Lagergeld sowie auf Zinsen für Darlehen, Vorschüsse, Verwendungen . . 252

$\S 355$ Das Kontokorrentverhältnis 257

\$356 Fortbestand von Sicherheiten für Einzelforderungen . . . 310

§ 357 Pfändung der Ansprüche eines Kontokorrentbeteiligten 315

Anhang zu § 357. Die offene Rechnung oder uneigentliche laufende Rechnung . . . . . . 317 95

$\S 358$ Die Geschäftszeit als Erfüllungszeit. . . . . . . . 320 Bis hierher Lieferung 2; Material bis Mitte 1954 verarbeitet

$\S 359$ Besondere Zeitbestimmungen . . . . . . . . . . 321

Anhang zu $§ 359$. Die Erfüllungszeit 322 
8360 Gattungsschuld Sette

\$361 Maß, Gewicht, Währung, Zeitrechnung, Entfernungen 334

Anhang zu $\S 361$. Das Zustandekommen des Vertrags.

$\S \S 145-155$ BGB . . . . . 346

$\S 362$ Schweigen als Annahme des Vertragsantrags . . . . . 398

$\S 363$ Die kaufmännischen Orderpapiere . . . . . . . 403

$\S 364$ Wirkungen des Indossaments 431

$\S 365$ Form des Indossaments, Legitimation des Besitzers. Abhandengekommene und vernichtete Orderpapiere. . 440 Bis hlerher Lleferung 3; Material bis Mitte 1956 verarbeltet

Anhang I zu $\$ 365$.

A. Der Bank- und Girovertrag 447

B. Die Banküberweisung . . . 501

C. Das Dokumentenakkreditiv 574

Anhang II zu \$365. Rekta- und Inhaberpapiere . . . . . . 620

Bis hierher Lieferung 4; Material bis Ende 1961 verarbeitet

$\S 366$ Der Schutz des gutgläubigen Eigentums- und Pfanderwerbs an beweglichen Sachen und Inhaberpapieren, insbesondere des gutgläubigen Rechtserwerbs von einem Kaufmann. Ausgleichung des entstandenen Schadens. Guter Glaube an die Verfügungsbefugnis . . . . .

$\S 367$ Einschränkung des Schutzes des gutgläubigen Rechtserwerbs an abhanden gekommenen Inhaberpapieren und ihnen gleichgestellten anderen Wertpapieren durch einen Bankier . . . . . . . . 683

$\S 368$ Die Verwertung des Pfandes. - Darstellung des Vertragspfandrechts, der Sicherungsübereignung und der Sicherungsabtretung . . . . . . 688

I. Gegenstand des Pfandrechts 693

II. Art der Bestellung des Pfandrechts . . . . . 698

III. Schutz des gutgläubigen Pfanderwerbs . . . . 709

IV. Wirkungen des Pfanderwerbs .. . . . . . 710

V. Uneigentliches Pfandrecht. 736
VI. Die gesetzlichen Pfandrechte 737

VII. Sicherungsübereignung und Sicherungsabtretung . . . 739

VIII. Inkassomandat mit Inkassovollmacht; Inkassoabtretung; Inkassoermächtigung 799 Bis hierher Lleferung 5; Material bis Anfang 1962 verarbeitet

Vorbemerkung vor $\S 369$. Das Zurückbehaltungsrecht des BGB . 805

§ 369 Das kaufmännische Zurückbehaltungsrecht . . . . . 819

§370 Das kaufmännische Notzurückbehaltungsrecht. . . . 839

$\S 371$ Die Befriedigung aus der zurückbehaltenen Sache. . 841

$\$ 372$ Die Befriedigung beim Eigentumswechsel . . . . 846

Anhang zu $\$ 372$. Ort und Zeit der Erfüllung . . . . . . 847

I. Ort der Erfüllung, zwischenstaatliches Recht. Die gesetzliche Regel. Änderung durch Vereinbarung. Die Bedeutung des Schweigens, insbesondere beim Bestätigungsschreiben. Erfüllungsort beim Kauf . . . . . . 850

II. Zeit der Erfüllung. Die Zahlungsabreden . . . . . 888

III. Der Bestimmungsort der Leistung, insbesondere bei Geldzahlungen. Die Lehre von der Geldübersendungspflicht: Wohnsitz des Gläubigers; Übermittlung auf Kosten und Gefahr des Schuldners; U̇bermittlung des Geldes an den Gläubiger durch Barzahlung; bargeldsparende Zahlung; bargeldlose Zahlung; Organisation und Träger des bargeldlosen Zahlungsverkehrs; die allgemeinen Geschäftsbedingungen der Bundesbank (Auszug) und der Banken (Auszug); Zahlungen aus öffentlichen Kassen; Erteilung der Quittung und Rückgabe des Schuldscheines durch den Gläubiger . . 902 Bis hierher Lieferung 6; Materlal bis Ende 1962 verarbeitet

Sachregister . . . . . . . 945 